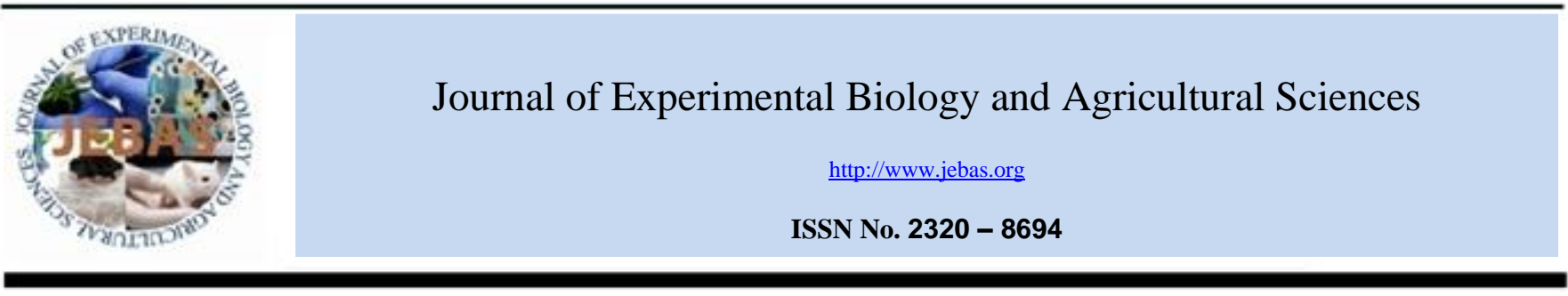

\title{
WILD EDIBLE MUSHROOMS OF NAGALAND, INDIA: A POTENTIAL FOOD RESOURCE
}

\section{Toshinungla Ao, Chitta Ranjan Deb* and Neilazonuo Khruomo}

Department of Botany, Nagaland University, Lumami 798 627, Nagaland, India

Received - November 27, 2015; Revision - December 24, 2015; Accepted - January 31, 2016

Available Online - February 20, 2016

DOI: http://dx.doi.org/10.18006/2015.4(1).59.65

\section{KEYWORDS}

Food security

Natural resource

Socio-economic value

Underutilized

WEM

\section{ABSTRACT}

Wild edible mushrooms (WEM) are known for its medicinal and nutritional value across the globe. WEM have become one of the most prized after food especially in the developed countries where people are mostly health conscious. The present study throws light on the diverse flora of WEMs of Nagaland and how it can be income generator for the tribal people with proper research in this aspect. Till now, the knowledge of distinguishing between edible and non-edible varieties is only confined to people who go for mushroom hunting. As such the indigenous knowledge remains with only those few people involved. The current data can pave the way for future research work and also make people aware of the many varieties of WEMs available in the state. A total of 33 WEMs were collected and identified during the peak mushroom season of the state i.e. from end May to September of every study year.
* Corresponding author

E-mail: debchitta@ rediffmail.com (Chitta Ranjan Deb)

Peer review under responsibility of Journal of Experimental Biology and Agricultural Sciences.

Production and Hosting by Horizon Publisher (http://publisher.jebas.org/index.html).

All rights reserved.
All the article published by Journal of Experimental Biology and Agricultural Sciences is licensed under a Creative Commons Attribution-NonCommercial 4.0 International License Based on a work at www.jebas.org.

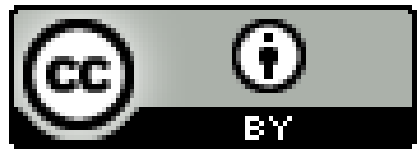




\section{Introduction}

Wild edible fungi have been collected and consumed by people for thousands of years. Wild edible fungi are important sources of nutrition and medicines. Around 2000 species of mushrooms are considered safe for human consumption and about 650 of these possess medicinal properties (Rai et al., 2005). Mushrooms have a long association with humankind and provide profound biological and economical impact. Since time immemorial, wild mushrooms have been consumed by man (Das, 2010). Edible mushrooms have high content of proteins, vitamins, minerals, fibers, trace elements and low/no calories and cholesterol (Murugkar \& Subbulakshmi, 2005). Mushrooms have been used in folk medicine for thousands of years and are considered to be Neutralceuticals while others can produce potent Neutriceuticals (Ribeiro et al., 2005). Due to its traditional usage, Trametes versicolor has been considered among the 25 major medicinal macrofungi worldwide (Boa, 2004) and polysaccharo-peptides purified from this species, show experimental immune-modulatory and anti-cancer effects (Cheng \& Leung, 2008). Besides, mushrooms are known to be rich sources of various bioactive substances like anti-bacterial, anti-fungal, anti-viral, antiparasitic, anti-oxidant, anti-inflammatory, anti-proliferative, anti-cancer, anti-tumour, cytotoxic, anti-HIV, hypocholesterolemic, anti-diabetic, anti-coagulant, hepatoprotective compounds, among others (Wasser \& Weis, 1999; Ajith \& Janardhanan, 2007).

Mushrooms are a boon for progress in developing countries like India with rich biodiversity especially in the field of food, medicine and unemployment (Wani et al., 2010). World production of mushroom exceeds 3 million tons worth a market value of U.S \$ 10 billion. Netherlands, Poland, Ireland and Belgium are major exporting countries of fresh mushrooms in the world. China is the largest exporter of preserved mushrooms and Netherlands and Spain are the other major countries (Harsh \& Joshi, 2008). Germany, U.S.A and France are considered to be major importing countries of prepared and preserved mushrooms. Till 2008 India ranked $6^{\text {th }}$ as an exporter of mushrooms. India has a great potential to be an important producer of mushroom in the future and currently ranks $54^{\text {th }}$ in the world in producing mushrooms. Edible mushrooms are valuable sources of nutrients and bioactive compounds in addition to its rich flavors and culinary features.

Recently mushrooms have become increasingly popular as functional foods for its potential beneficial effects on human health (Guillamon et al., 2010). Modern pharmacological research confirms large parts of traditional knowledge regarding the medicinal effects of mushrooms due to their antifungal, antibacterial, antioxidant and antiviral properties (Wani et al., 2010). Wild edible mushrooms are not well documented in many countries, poorly studied and underutilized though they are rich source of non wood forest product. There is no systematic survey and study on mushroom harvest, its market and income generation potential (Tibuhwa, 2013). The FAO of the UN has emphasized the adoption of mushrooms as an ideal food for developing countries and its contribution to global food security.

Wild edible mushrooms are used as food and medicine by the indigenous tribes of Similipal Biosphere Reserve (SBR) of Odisha, India. More than ten ethnic groups of SBR were found to be mycophilic and have extensive traditional mycological knowledge (Sachan et al. 2013). The mushrooms identified in the SBR are native to many parts of India which were reported by some authors in the North-Eastern hills of India (Verma et al., 1995; Singh et al., 2007; Tanti et al., 2011); North Western Himalayas (Atri et al., 1997) and Kanyakumari district (Davidson et al., 2012). The northeast region of India is known for its rich biodiversity. The high humidity during monsoon period provides ideal agro-climatic conditions for the growth of mushrooms. The people of Nagaland are highly known for coveting wild edible mushrooms. Mushrooms are highly prized delicacy of the state. Very few works has been done on wild edible mushrooms in Nagaland (Kumar et al., 2013). In most of these reports the mushroom resources are ill presented. The purpose of the present study was to bring to light the rich diversity of WEMs of Nagaland and its potential as a valuable food resource.

\section{Materials and Methods}

\section{Survey Area}

Nagaland is located in the North Eastern region of India with total geographic area of 16,579 sq Km. Nagaland shares borders with Myanmar in the East, Assam in the West, Arunachal Pradesh and a part of Assam in the North and Manipur in the South. It lies between $93^{\circ} 15^{\prime}$ to $95^{\circ} 15^{\prime} \mathrm{E}$ and $25^{\circ} 10^{\prime}$ to $27^{\circ} 4^{\prime} \mathrm{N}$. According to the meteorological data of the state the average annual rainfall ranges between 2000-2500 $\mathrm{mm}$ while, temperature during summer ranges from $16-31^{\circ} \mathrm{C}$ and drops as low as $4^{\circ} \mathrm{C}$ during winter. During the present study regular surveys and collection were carried out in various districts and market areas of Nagaland from October 2013May 2015 during the peak mushroom season of the state. Forest areas and market places of Mokokchung, Zunheboto, Kohima, Tuensang, Phek and Wokha were surveyed during this period. Local markets were surveyed to know about the wild varieties sold during the season and regular mushroom collectors were interviewed to gain more knowledge about the hunting areas.

Wild edible mushrooms were collected in silver foil/collection boxes and brought to the laboratory for identification. Mushrooms with leathery texture were preserved in $4 \%(\mathrm{v} / \mathrm{v})$ formaldehyde solution and mushrooms with soft texture were preserved in $2 \%(\mathrm{v} / \mathrm{v})$ formaldehyde solution and maintained as herbarium specimens. 
Table 1 List of Wild Edible Mushrooms (WEM) found in Nagaland, India.

\section{Name of Species (Family)}

Auricularia auricula-judae (Bull.) Quél (Auriculariaceae)

A. polytricha (Mont.) Sacc (Auriculariaceae)

Cantharellus cibarius (Fr.) (Cantharellaceae)

Lactarius piperatus (L.) Pers. (Russulaceae)

Lactarius volemus (Fr.) (Russulaceae)

Lentinula edodes (Berk.) Pegler (Omphalotaceae)

Hericium cirrhatum (Pers.) Nikol (Hericiaceae)

Dacryopinax spathularia (Schwein) G. W. Martin (Dacrymycetaceae)

Schizophyllum commune Fr. (Schizophyllaceae)

Strobilomyces strobilaceus (Scop.) Berk (Boletaceae)

Amanita strobiliformis (Paulet ex Vittad.) (Amanitaceae)

Boletus edulis Bull. (Boletaceae)

Tricholoma imbricatum (Fr.) P. Kumm. (Tricholomataceae)

Pleurotus pulmonarius (Fr.) Quél. (Pleurotaceae)

Clavaria fragilis Holmsk. (Clavariaceae)

Tremella fuciformis Berk. (Tremellaceae)

Lentinus squarrosulus Mont. Singer (Polyporaceae)

Hygrocybe conica (Schaeff.) P. Kumm (Hygrophoraceae)

Russula heterophylla (Fr.) Fr. (Russulaceae)

Suillus luteus (L.) Roussel (Suillaceae)

Xerocomellus chrysenteron (Bull.) Šutara (Boletaceae)

Suillus pictus (Peck) A.H. Sm. \& Thiers (Suillaceae)

Laccaria tortilis (Bolton) Cooke (Hydnangiaceae)

Melanoleuca grammopodia (Bull.) M. (Tricholomataceae)

Aleuria aurantia (Pers.) Fuckel (Pyronemataceae)

Macrolepiota albuminosa (Berk.) Pegler (Agaricaceae)

Termitomyces heimii Natarajan (Lyophyllaceae)

Lentinus sp. (Polyporaceae)

Termitomyces eurhizus (Berk.) R. Heim (Lyophyllaceae)

Lycoperdon perlatum Pers. (Agaricaceae)

Laetiporus sulphureus (Bull.) Murr. (Polyporaceae)

Coprinus comatus (O.F. Müll.) Pers. (Agaricaceae)

Pleurotus citrinopileatus Singer (Pleurotaceae)
Habitat

On dead stumps and branches of sub-tropical and temperate trees especially Alnus species. In clusters on rotten or dead and decaying stumps and twigs

Found under Lithocarpus in sub-tropical forests

Under sub-tropical semi-evergreen forest

Under sub-tropical semi-evergreen forests including pine

On trunks of Oak trees

On trunks of semi-evergreen and temperate trees

On dead and decaying logs in large group

On branches of dead wood and cut timber

Grows in association with semi-evergreen and coniferous trees

Under sub-tropical semi evergreen forest trees

Under coniferous and semi-evergreen forest types

In coniferous woods, especially with pine

In clusters on cut timber and fallen $\log$

Grows in clusters on ground amongst leaf litters and in fields

On dead or fallen branches of broadleaved trees

On dead stumps of trees like Oak

In grass in fields after burning the area

Under Lithocarpus and Castanopsis in sub-tropical forests

Under coniferous especially pine

Under sub-tropical semi-evergreen forests including pine

Under sub-tropical semi-evergreen forests

On bare soil in damp woods

Found to grow on leaf mulch or composted soil in field

Found to grow in groups on soil amongst grasses or on bare soil or at roadside

Grows on termite mounds in grassy fields

Found to grow on termite mounds and clayey soil

Grows on tree trunks and dead barks of Oaks

Grows in groups on ground in termite mount soil

Grows in fields, roadsides, in woods and amongst fallen leaf litter

Grows on dead stumps as well as living tree trunk of hardwoods and oaks

Grows amongst grasses in sub-tropical forests

Grows on trunks of hardwood
Season of collection

End May-November

September-Novembe

End June-October

June-Octobe

June-October

June-July

June-July

June-July

April-August

June-September

June-August

August-September

July-August

June-September

August-November

September-November June-August

June-July

October-January

September-November

July-November

June-November

August-November

June-October

August-November

May-August

May-August

End May-June

July-August

End April-September

July-September

May-Octobe

June-August
Accession No

NUBOT-TA-AA-01

NUBOT-TA-AP-02

NUBOT-TA-CC-03

NUBOT-TA-LP-04

NUBOT-TA-LV-05

NUBOT-TA-LE-06

NUBOT-TA-HC-07

NUBOT-TA-DS-08

NUBOT-TA-SC-09

NUBOT-TA-SS-12

NUBOT-TA-AS-19

NUBOT-TA-BE-22

NUBOT-TA-TI-27

NUBOT-TA-PP-28

NUBOT-TA-CF-35

NUBOT-TA-TF-37

NUBOT-TA-LS-40

NUBOT-TA-HC-41

NUBOT-TA-RH-44

NUBOT-TA-SL-46

NUBOT-TA-XC-48

NUBOT-TA-SP-49

NUBOT-TA-LT-51

NUBOT-TA-MG-61

NUBOT-TA-AA-62

NUBOT-TA-MA-63

NUBOT-TA-TH-64

NUBOT-TA-L-69

NUBOT-TA-TE-71

NUBOT-TA-LP-72

NUBOT-TA-LS-73

NUBOT-TA-CC-74

NUBOT-TA-PC-75 

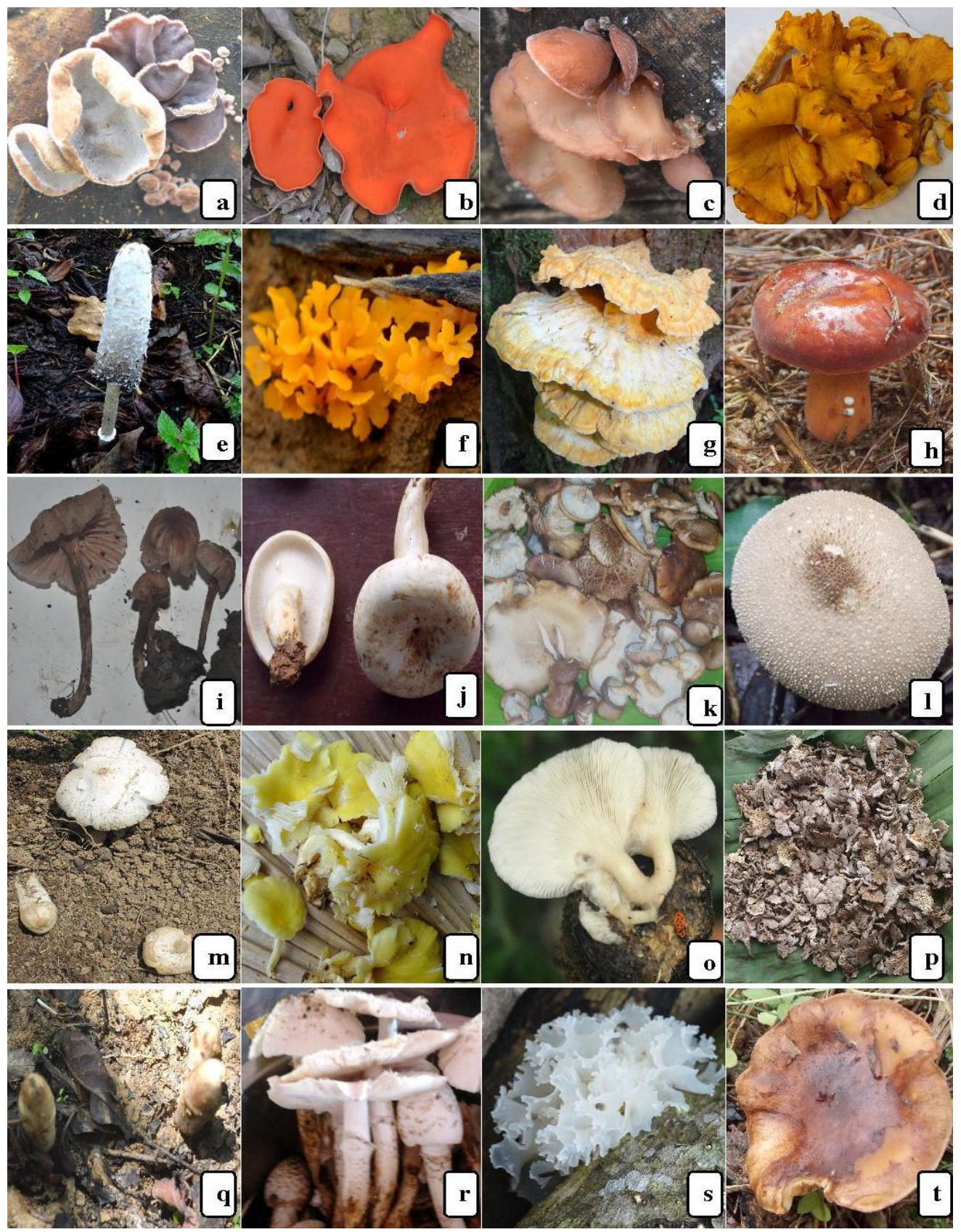

Figure 1 Some of the wild edible mushrooms of Nagaland; a. Auricularia polytricha, b. Aleuria aurantia, c. Auricularia judae, d.

Cantharellus cibarius, e. Coprinus comatus, f. Dacryopinax spathularia, g. Laetiporus sulphureus, h. Lactarius volemus, i. Laccaria tortilis, j. Lactarius piperatus, k. Lentinula edodes, 1. Lycoperdon perlatum, m. Macrolepiota albuminosa, n. Pleurotus citrinopileatus, o.

Pleurotus pulmonarius, p. Schizophyllum commune, q. Termitomyces eurrhizus, r. Termitomyces heimi, s. Tremella fuciformis, t. Tricholoma imbricatum.

A part of the collected materials were dried at $40-72^{\circ} \mathrm{C}$ using blowing hot air and kept for future references, characterization and documentation. The habitat, odor, morphology, spore print and adaptation to the environment studied prior to the preservation of the collected macro fungi. Identification of the collected mushrooms was done by standard microscopic methods (Roy \& De, 1996) and by studying the macroscopic and microscopic characters (David, 1986; Das, 2009; Philips, 2006). The mushroom specimens were deposited in the herbarium of Department of Botany, Nagaland University, Lumami, India with the accession numbers as mentioned in Table 1. 
3 Results

A total of 33 Wild Edible Mushroom (WEM) species belonging to Auriculariaceae, Cantharellaceae, Russulaceae, Polyporaceae, Hericiaceae, Dacrymycetaceae, Schizophyllaceae, Boletaceae, Amanitaceae, Tricholomataceae, Pleurotaceae, Clavariaceae, Tremellaceae, Hygrophoraceae, Suillaceae, Hydnangiaceae, Pyronemataceae, Agaricaceae and Lyophyllaceae were collected and identified as per various literatures (Table 1). Besides edible mushrooms, 9 species are used for medicinal purpose to cure different diseases (Table 2). Figure 1 shows some of the common wild edible mushrooms of Nagaland. Market surveys revealed that WEM are highly coveted food resource in Nagaland. The local people prepare soups, chutney, salads and various side dishes from mushrooms. During the season, there is high demand of edible varieties of WEMs and these are sold ranging from 50250 INR per packet at local markets. The prize varies depending on popularity, taste and demand. Some popular varieties available at local markets during the season are Schizophyllum commune, Lentinus edodes, L. squarrosulus, Termitomyces heimi, T. eurhizus, Auricularia auricula-judae, Lactarius volemus, and Pleurotus pulmonarius. S. commune and L. edodes are sold in dried form throughout the year till stocks last with the local people.

\section{Discussions}

Nagaland is one of the North Eastern states of India which is agro-climatically very rich and supports the growth of many wild mushrooms. Unfortunately till date there is no systematic survey of wild edible mushrooms in the state. Indigenous knowledge possessed by the local people about WEMs will provide significant opportunities to develop micro-enterprises and entrepreneurship. This can be a means of achieving sustainability. Mushroom hunting is not gender oriented in the state i.e. both men and women are equally involved. Folk taxonomy through traditional knowledge and experience is usually used to identify edible mushrooms from poisonous ones. Naming of the species is done in local dialect to keep memory and transfer the knowledge from one generation to the next. The study promotes awareness to harvest and exploit this underutilized local resource, which will provide nutritious food and employment opportunities especially to the disadvantaged groups (i.e. unemployed and old people) (Kumar et al., 2013; Sachan et al. 2013; Tanti et al., 2011; Tibuhwa, 2013).

The exploitation of WEM would contribute significantly in boosting the economy and at the same time, food security is checked. Mushrooms are a source of income generator especially for rural areas. The cultivation of WEM hardly causes any effect on the environment in fact they act as ecological indicators. As such the study calls for awareness and cooperation from forest conservers to allow mushroom gatherers to freely collect this non wood forest resource which is highly underutilized. The present work also highlights the ethno-medicinal potential of the state. The uses (nutritional and medicinal values, neutriceuticals and neutraceutical compounds) of WEM is likely to be lost if these are not properly documented and screened. Further studies need to be carried out in order to assess the ethno-medicinal potential of WEMs for discovery of novel compounds for their pharmaceutical applications.

The present work may lead to the creation of a database for WEM of the state as no such work has been carried out in depth. The first phase of this study enumerates the wild edible mushrooms of Nagaland. Works on nutritional analysis, molecular profiling of wild edible mushrooms is in progress. During recent times, cultivated mushrooms have gained much attention because of the many health benefits of mushrooms but unfortunately in remote regions of the world like Nagaland no such markets are available for the local people to enjoy the highly popular cultivated mushrooms. In such circumstances, the wild edible mushrooms which are available in the state should be brought to light so that the people can reap the benefits of consuming edible mushrooms like the rest of the world. Moreover, with proper research and infrastructure facilities, WEM can be commercialized which can play a key role in the socio-economic upliftment of the people.

Table 2 Medicinal uses of WEM as described by other researchers.

\begin{tabular}{|ll|}
\hline Name of the species & Medicinal uses \\
\hline Auricularia auricula-judae & Anti-tumor, anticoagulant, hypocholesterolemic \\
\hline Auricularia polytricha & Anti-coagulant, hypocholesterolemic \\
\hline Pleurotus pulmonarius & Anti-HIV, hyperglycemic \\
\hline Cantharellus cibarius & Anti-microbial \\
\hline Schizophyllum commune & Anti-cancer (drug- Schizophyllan) \\
\hline Lentinula edodes & Anti-tumor, anti-HIV, natural antidote \\
\hline Lactarius piperatus & Anti-tumor, anti-bacterial, anti-oxidant \\
\hline Lycoperdon perlatum & Antimicrobial and Antifungal (lycoperdic acid) \\
\hline Lentinus squarrosulus & Used as neutraceutical \\
\hline
\end{tabular}

Sources: Chang \& Miles, 2004; Das, 2010; Patel et al., 2012; Sachan et al., 2013; Sharma \& Atri, 2014. 


\section{Acknowledgement}

The authors are thankful to the University Grants Commission, Govt. of India, New Delhi for financial help through the UGCSAP (DRS-III) program to the Department of Botany. The infrastructure and facility used from the Institutional Biotech Hub, Department of Botany, Nagaland University are duly acknowledged.

\section{Conflict of Interest}

Authors would hereby declare that there is no conflict of interests.

\section{Reference}

Ajith TA, Janardhanan KK (2007) Indian medicinal mushrooms as a source of antioxidant and antitumor agents. Journal of Clinical Biochemistry and Nutrition 40: 157-162.

Atri NS, Saini SS, Saini MK (1997) Studies on genus Russula Pers. from North Western Himalayas. Mushroom Research 6: $1-6$.

Boa E (2004) Wild Edible Fungi, A Global Overview of Their Use and Importance to People., Non-Wood Forest Products Series no. 17. FAO, Rome.

Chang S, Miles GP (2004) Mushrooms: Cultivation, nutritional value, medicinal effects and environmental impact. CRC Press, USA, Pp 436.

Cheng KF, Leung PC (2008) General review of polysaccharopeptides (PSP) from C. versicolor: Pharmacological and clinical studies. Cancer Therapy 6: 117130 .

Das K (2009) Mushrooms of Sikkim I: Barsey Rhododendron Sanctuary, Sikkim State Biodiversity Board, Gangtok and Botanical Survey of India, Kolkata, India, Pp 1-160.

Das K (2010) Diversity and conservation of wild mushrooms in Sikkim with special reference to Barsey Rhododendron Sanctuary. NeBio 1: 1-13.

David A (1986) Mushrooms demystified: A comprehensive guide to the fleshy fungi, Ten Speed Press, Berkeley, CA Pp 406- 410.

Davidson SS, Johnsy G, Samuel SA, Kaviyarsan V (2012) Mushrooms in the food culture of the Kanni tribe of Kanyakumari district. Indian Journal of Traditional Knowledge 11: 150-153.
Guillamón E, Lafuente AG, Lozano M, D’Arrigo M, Rostagno MA, Villares A, Martínez JA (2010) Edible mushrooms: Role in the prevention of cardiovascular diseases. Fitoterapia 81: $715-723$.

Harsh NSK, Joshi K (2008) Mushrooms: The vegetables of future. Indian S \& T for Rural India Inclusive Growth 8: 663665 .

Kumar R, Tapwal A, Pandey S, Borah RK, Borah D, Borgohain J (2013) Macro-fungal diversity and nutrient content of some edible mushrooms of Nagaland, India. Bioscience 5: 1-7. DOI: 10.13057/nusbiosci/n050101.

Murugkar DA, Subbulakshmi G (2005) Nutritional value of edible wild mushrooms collected from the Khasi hills, Meghalaya. Food Chemistry 89: 599-603.

Patel Y, Naraian R, Singh VK (2012) Medicinal Properties of Pleurotus Species (Oyster Mushroom): A Review. World Journal of Fungal and Plant Biology 3: 01-12. DOI: 10.5829/idosi.wjfpb.2012.3.1.303.

Philips R (2006) Mushrooms, Pan Macmillan, London.

Rai M, Tidke G, Wasser SP (2005) Therapeutic potential of mushrooms. Natural Product Radiation 4: 246-257.

Ribeiro B, Valentao P, Baptista P, Seabra RM, Andrade PB (2007) Phenolic compounds, organic acids profiles and antioxidative properties of beefsteak fungus (Fistulina hepatica). Food Chemistry and Toxicology 45: 1805-1813.

Roy A, De AB (1996) Polyporaceae of India, International Book Distributors, Dehradun, India.

Sachan SKS, Patra JK, Thatoi HN (2013) Indigenous knowledge of ethnic tribes for utilization of wild mushrooms as food and medicine in Similipal Biosphere Reserve, Odisha, India. Journal of Agricultural Technology 9: 403-416.

Sharma SK, Atri NS (2014) Nutraceutical composition of wild species of genus Lentinus Fr. from Northern India. CREAM, 4: 11-32. DOI: $10.5943 / \mathrm{cream} / 4 / 1 / 2$.

Singh TC, Nivedita L, Singh NI (2007) Endemic bioresoures of India conservation and sustainable development with special reference to North-East India. In: Singh NI, Singh B, Singh MP (eds.) Endemic Bioresources of India. Dehradun, India, Pp 67-94.

Tanti B, Gurung L, Sarma GC (2011) Wild edible fungal resource used by the ethnic tribes of Nagaland, India. Indian Journal of Traditional Knowledge 10: 512-515. 
Tibuhwa DD (2013) Wild mushroom - an underutilized healthy food resource and income generator: experience from Tanzania rural areas. Journal of Ethnobiology Ethnomedicines 9: 49.

Verma RN, Singh GB, Singh SM (1995) Mushroom flora of North-Eastern Hill. In: Chandra KL; Sharma SR (Eds.) Advances in horticulture mushroom, Molhotra Publication, New Delhi, India, Pp 329-349.
Wani BA, Bodha RH, Wani AH (2010) Nutritional and medicinal importance of mushrooms. Journal of Medicinal Plants Research 4: 2598-2604.

Wasser SP, Weis AL (1999) Medicinal properties of substances occurring in higher basidiomycetes mushrooms: current perspective. International Journal of Medicinal Mushrooms 1: 31-62. 